American Journal of Applied Sciences 3 (4): 1814-1818, 2006

ISSN 1546-9239

(C) 2006 Science Publications

\title{
Service Loyalty Measurement Scale: A Reliability Assessment
}

\author{
${ }^{1}$ J. Clement Sudhahar, ${ }^{2}$ Duraipandian Israel, ${ }^{3}$ A.Prabhu Britto and ${ }^{4}$ M.Selvam \\ ${ }^{1}$ School of Management, Karunya Deemed University, Coimbatore, India \\ ${ }^{2}$ XLRI, Jamshedpur, India \\ ${ }^{3}$ Center for Medical Electronics, Department of ECE, Anna University, Chennai, India \\ ${ }^{4}$ Department of Commerce, Bharathidasan University, Trichy, India
}

\begin{abstract}
This research article demonstrates the application of Confirmatory Factor Analysis (CFA) in the scale development process of measuring the construct Service Loyalty (SERVLOYAL). The conceptualization of SERVLOYAL is presented, the dimensions forming the SERVLOYAL construct are figured out. The nitty-gritty of CFA is discussed. And the results of CFA analysis for SERVLOYAL scale developed are found to be reliable. This empirical study provides a solid foundation for further research in CFA and SEM applications.
\end{abstract}

Key words: Service loyalty, reliability, measurement scale

\section{INTRODUCTION}

The act of maintaining long-term relationship with customers has been proving to be beneficial for the corporate of any rung, be it profitability or loyalty, irrespective of the sectors they belong to. In today's highly competitive environment, organizations should protect the long-term interest of the customers and hence should seek the ways through which the customer loyalty toward the organizations will be forged. Marketers opine that these long-term relationships with the customers would enhance their profitability ${ }^{[1-3]}$, increased sales, lower costs and other tangible benefits ${ }^{[4]}$. The time has come for the firms to consider this customer loyalty as a source of competitive advantage ${ }^{[5]}$. It has been established that the customers will not be impressed by only the core product attributes as other firms are also providing similar offerings. The study of customer loyalty and business performance has been a focus in the customer relationship management ${ }^{[6,7]}$. While the study on brand loyalty has been the topic of research in the past, numerous research articles appearing in journals betokening the development and conceptualization of the service loyalty models. More than a dozen of articles have been published on customer loyalty in retail banking market ${ }^{[8]}$ alone as it has been recognized that many banks have introduced innovative products and service ${ }^{[9]}$ and that it is less expensive to retain a customer than acquiring a new one. The longer the customer stays with an organisation, the more positive outcome he generates which include increase in the value of purchase, increase in the number of purchases and the customers' better understanding of Organisational and vice-versa and more positive wordof-mouth ${ }^{[10]}$.
Service loyalty literature recap: Several contributions have been made in service marketing literature in measuring the service loyalty (SERVLOYAL). Significantly, factors such as service quality ${ }^{[11]}$, service satisfaction $^{[11,12]}$, image ${ }^{[13,14]}$, values $^{[15]}$, commitment $^{[16,17]}$ and trust ${ }^{[12]}$ are identified to have an impact on SERVLOYAL. Since service is peculiar that involves personal encounter and also has a bit of perceived risk in the consumption of the same ${ }^{[18,19]}$ the measurement of loyalty has become a subject for discussion from a radically different perspective from that of a product loyalty. The term loyalty has been defined as a degree of continuity in patronage ${ }^{[9]}$, customers' disposition in terms of preferences and intentions ${ }^{[20]}$ and a psychological process resulting in brand commitment ${ }^{[21]}$. Further, different measures of service loyalty have been utilized in different industries. While more number of articles on the measurement of SERVLOYAL is in extant for a retail banking service than for any other service sector, it was construed imperative by the authors to develop an allencompassing measurement for SERVLOYAL in utilizing the various ingredients that would reflect the SERVLOYAL construct. Devoiding the technical nuances, endeavors have been made in this article to present ultimate scale developed for SERVLOYAL utilizing a confirmatory factor analysis (CFA) model.

Conceptualisation: SERVLOYAL is conceptualized as an interaction of attitude and behaviour ${ }^{[1]}$ such that the behaviour (loyalty) is determined by the strength of relationship between relative attitude and repeat patronage. Extending this, the loyalty dimensions or concepts are to include behavioral, attitudinal and cognitive processes. The attitudinal dimensions of loyalty were to include attributes such as word-or-

Corresponding Author: J. Clement Sudhahar, Asst. Professor, School of Management, Karunya Deemed University, Coimbatore India 
mouth, complaining behaviour and purchase intentions ${ }^{[22]}$. The behavioral loyalty measures include attributes such as brand allegiance, price elasticity, share of category (number of times a brand is purchased in a given period) and price until switching ${ }^{[23]}$. The cognitive loyalty component includes attributes like preference to the service organisation, the belief that the service organisation provides best offer and suiting customer needs $^{[24]}$. But it should be mentioned that the loyalty dimension is to also include factors such as commitment and trust attributes, even though the utility of these constructs by Luarn and $\operatorname{Lin}^{[12]}$ was meant to consider them as antecedents to loyalty rather than components of loyalty.

Based on the review of the aforesaid earlier studies, the authors identified the SERVLOYAL constructs into the following seven dimensions for scale construction process.

1. Behavioral dimension

2. Attitudinal dimension

3. Cognitive dimension

4. Conative dimension

5. Affective dimension

6. Trust dimension

7. Commitment dimension

Method: The scales developed by the previous researchers for the measurement of SERVLOYAL laid a strong foundation for evolving items for SERVLOYAL measurement for the present study. Additionally, the items required for each of the dimensions were also developed out of discussions with the doctoral fellows in the area of services marketing and also the discussion held with the bank executives across private, public and foreign sector banks located in the state of Tamil Nadu. In this way, a total number of 43 statements were developed and purified through substantiation in the literature. These 43 items were then further refined and the final list included 31 items. A content validity of the said items with 10 bank executives located in the city of Coimbatore was done. The executives were asked to check for the appropriateness of assigning these 31 items into a preset seven dimensions. Three statements were found inappropriate for inclusion in any of the dimensions by majority executives and were therefore eliminated from forming the scale. Hence a pool of 28 statements was finalized for inclusion in the final scale. The scale items were measured on a five-point scale ranging from "strongly agree $(=1)$ " to "strongly disagree $(=5)$ ". Four statements were reverse-coded. A total number of 175 customers in different banks that included private, public and foreign sectors were contacted for their response. The collected response $(n=137)$ were analyzed for their scale properties through a confirmatory factor analysis using a Structural Equation Modeling (SEM) package through Amos version 5.0.
Confirmatory factor analysis: Confirmatory factor analysis (CFA) seeks to determine if the number of factors and the loadings of measured (indicator) variables on them conform to what is expected on the basis of pre-established theory. Indicator variables are selected on the basis of prior theory and factor analysis is used to see if they load as predicted on the expected number of factors. The researcher's à priori assumption is that each factor (the number and labels of which may be specified à priori) is associated with a specified subset of indicator variables. A minimum requirement of confirmatory factor analysis is that one hypothesize beforehand the number of factors in the model, but usually also it will be posited that the expectations about which variables will load on which factors ${ }^{[25]}$. There are two approaches to confirmatory factor analysis:

The Traditional Method: Confirmatory factor analysis can be accomplished through any generalpurpose statistical package which supports factor analysis. Note that for SEM CFA one uses principle axis factoring (PAF) rather than principle components analysis (PCA) as the type of factoring. This method allows the researcher to examine factor loadings of indicator variables to determine if they load on latent variables (factors) as predicted by the researcher's model. This can provide a more detailed insight into the measurement model than can the use of singlecoefficient goodness of fit measures used in the SEM approach. As such the traditional method is a useful analytic supplement to the SEM CFA approach when the measurement model merits closer examination.

The SEM Approach: Confirmatory factor analysis can mean the analysis of alternative measurement (factor) models using a structural equation modeling package such as AMOS or LISREL. While SEM is typically used to model causal relationships among latent variables (factors), it is equally possible to use SEM to explore CFA measurement models. This is done by removing from the model all straight arrows connecting latent variables, adding curved arrows representing covariance between every pair of latent variables and leaving in the straight arrows from each latent variable to its indicator variables as well as leaving in the straight arrows from error and disturbance terms to their respective variables. Such a measurement model is run like any other model and is evaluated like other models, using goodness of fit measures generated by the SEM package.

Using SEM, a researcher can explore CFA models with or without the assumption of certain correlations among the error terms of the indicator variables. Such measurement error terms represent causes of variance due to unmeasured variables as well as random measurement error.

Depending on theory, it may well be that the researcher should assume unmeasured causal variables will be shared by indicators or will correlate and thus 
Table 1: CFA Results for SERVLOYAL Scale

\begin{tabular}{|c|c|c|c|c|}
\hline Dimensions & $\begin{array}{l}\text { Coefficient } \\
\text { Alpha }\end{array}$ & $\begin{array}{l}\text { CFA } \\
\text { Loadingsa }\end{array}$ & Residualb & $\begin{array}{l}\text { T- } \\
\text { Valuec }\end{array}$ \\
\hline Behavioral & 0.88 & & & \\
\hline a. I will transact with this bank again for future needs & & 0.87 & 0.24 & 23.13 \\
\hline b. I will try new services that are provided by this bank & & 0.82 & 0.33 & 21.61 \\
\hline c. I will recommend other people to patronize to this bank & & 0.74 & 0.45 & 20.69 \\
\hline d. I will say positive things to other people about the services provided at this bank & & 0.77 & 0.41 & 18.91 \\
\hline Attitudinal & 0.87 & & & \\
\hline a. I will continue to patronize this bank even if the service charges are increased moderately & & 0.86 & 0.26 & 17.23 \\
\hline b. I have strong preference to this bank & & 0.91 & 0.17 & 21.23 \\
\hline c. I will keep patronizing this bank regardless of everything being changed somewhat & & 0.67 & 0.55 & 13.57 \\
\hline d. I am likely to pay a little bit more for using the services of this bank & & 0.73 & 0.47 & 22.14 \\
\hline Cognitive & 0.86 & & & \\
\hline a. To me, this bank would rank first among the other banks & & 0.78 & 0.39 & 20.73 \\
\hline b.I would patronize this bank for a long period of time & & 0.83 & 0.31 & 22.44 \\
\hline c.I will deal exclusively with this bank & & 0.79 & 0.38 & 21.79 \\
\hline d.I think of this bank as my bank & & 0.67 & 0.55 & 14.84 \\
\hline e. The bank I patronize reflect a lot about who I am & & 0.61 & 0.63 & 13.26 \\
\hline Conative & 0.87 & & & \\
\hline a. I have found this bank better than others & & 0.87 & 0.24 & 24.77 \\
\hline b. I always find the terms of this bank are inferior. & & 0.82 & 0.33 & 23.26 \\
\hline c. Repeatedly, the performance of this bank is superior to that of competitor's one & & 0.81 & 0.34 & 22.01 \\
\hline Affective & 0.89 & & & \\
\hline a. I dislike the bank terms & & 0.72 & 0.48 & 21.95 \\
\hline b.I like the performances and services of the bank & & 0.85 & 0.28 & 26.30 \\
\hline c.I have a negative attitude toward this bank & & 0.83 & 0.31 & 22.46 \\
\hline d.I am satisfied with my decision to stay with this bank & & 0.86 & 0.26 & 26.86 \\
\hline Trust & 0.90 & & & \\
\hline a. This bank is like a friend to me & & 0.89 & 0.21 & 26.49 \\
\hline b. The bank employees go out of way for me & & 0.83 & 0.31 & 22.91 \\
\hline c. The people in the bank respond caringly when I share my problems & & 0.87 & 0.24 & 25.98 \\
\hline d. The bank personnel are filled with professionalism and dedication & & 0.76 & 0.42 & 20.59 \\
\hline Commitment & 0.91 & & & \\
\hline a. I am very committed to this bank & & 0.86 & 0.26 & 27.09 \\
\hline b. Even when I hear negative information about this bank, I still stick with this bank & & 84.00 & 0.30 & 25.33 \\
\hline c. I like switching from one bank to another & & 0.83 & 0.31 & 23.90 \\
\hline d. My continued association with this bank is important to me & & 0.85 & 0.28 & 26.88 \\
\hline Goodness of Fit Statistics & & & & \\
\hline Chi-square639.78 & & & & \\
\hline CFI .97 & & & & \\
\hline NFI .98 & & & & \\
\hline TLI .98 & & & & \\
\hline RMSEA .06 & & & & \\
\hline
\end{tabular}

SEM testing may well be merited. That is, including correlated measurement error in the model tests the possibility that indicator variables correlate not just because of being caused by a common factor, but also due to common or correlated unmeasured variables. This possibility would be ruled out if the fit of the model specifying uncorrelated error terms was as good as the model with correlated error specified. In this way, testing of the confirmatory factor model may well be a desirable validation stage preliminary to the main use of SEM to model the causal relations among latent variables. In this study, the very same approach of testing the reliability of the scale sans validation is attempted. A major advancement in the assessment of psychometric properties in the scale development is through the application of confirmatory factor analysis (CFA), which is distinct from the conventional exploratory factor analysis (EFA). As a special case of Structural Equation Model (SEM), which is a statistical technique that combines multiple regression, factor analysis and path analysis, the CFA based on measurement model suggested by Joreskog ${ }^{[26]}$ is commonly used to examine the factor structure of latent variables. CFA analysis is based on the correlation matrix, means and standard deviations of each item.

\section{RESULTS AND DISCUSSION}

The CFA is performed by utilizing software such as LISREL (Linear Structural Relationships) or AMOS (Analysis of Moment Structure) and is widely used by researcher in the developed nations for scale construction purposes. The logic of CFA is that given a set of variables ( say, 28 items in the present study for 
seven-dimensions of behavioral, attitudinal, cognitive, conative, affective, trust and commitment), the model attempts to conform these dimensions. One major advantage of CFA over EFA is that CFA considers and eliminates the measurement errors in relating variables to the dimensions. To that extent, the results are reliable. Further, through $\mathrm{CFA}$, we can reduce the number of variables attached to a construct. Moreover, unlike EFA, the results obtained through CFA can be statistically tested for validation, which is unique. While validity tests are also done through CFA analysis, the present study does not discuss the validity assessment of SERVLOYAL scale developed. An initial analysis of the obtained data indicated that each item was distributed normally, since the skewness and kurtosis values did not violate the norms. After that, a Maximum Likelihood Estimation Method (MLE) for the parameter estimation was performed. An analysis of outliers was also done by examining the values of standardized residuals for each factor and was found that none of the factors crossed the recommended limit of $2.51^{[27]}$.

As shown in Table 1, the confirmatory factor analysis of the data collected using Amos 5.0 software indicate interesting insights in establishing the reliability assessment of SERVLOYAL scale construction. The loadings indicated in column 3 of the table suggest that all the items taken for scale construction qualify to form into the scale developed. This is due to the fact that the loadings are greater than .40 for all the items. The t-values associated with each item also signify the statistical relevance of inclusion of these items. The reliability assessment through coefficient alpha value for each construct is also well above the recommended level of conventional. $70^{[28]}$ thereby suggesting a high internal consistency and reliability for each SERVLOYAL dimension. The fit indices for the measurement model also are good, with the exception of chi-square value, which is found significant (it is insisted here that the chi-square should be insignificant reflecting a close association between the observed and the estimated covariance matrix for the variables). Overall, the CFA results suggest that the scale possesses sound reliability.

\section{CONCLUSION}

In conclusion it should be reiterated that this study is a maiden effort to develop a comprehensive scale to measure service loyalty. The present study investigated the appropriateness of seven dimensions of SERVLOYAL scale for use in the service marketing literature. The CFA results suggested that the sevendimension model fit the data well. The reliability coefficient for each dimension was found to be high (greater than .80) in all the cases. Furthermore, the parameter estimates indicate that each item in the scale developed contributes greater variance to the model.
However, the authors underscore that caution should be exercised before adapting the scale by researchers. That is, only the reliability aspect of SERVLOYAL scale has been assessed while it is of paramount importance that the scale should also possess a validity too, especially nomological, discriminant and convergent validities. As a pioneer one, the description present here simply betokens the need for development of SERVLOYAL for use in the service marketing research. The robustness of the measurement of items in terms of relationship among latent variables can always stand improvement. Therefore, future research is caller for to continuously refine this measurement scale and corroborate the findings of this empirical study. The effect of psychological and genetic predispositions to Service Loyalty has yet to be investigated and the same could also be attempted as a future study.

\section{REFERENCES}

1. Dick, A.S. and K. Basu, 1994. Customer loyalty: Toward an integrated conceptual framework. J. Acad. Market. Sci., 22: 99-133.

2. Garbarino, E. and M.S. Johnson, 1999. The different roles of satisfaction, trust and commitment in consumer relationships. J. Market., 63: 70-87.

3. Grossman, R.P., 1998. Developing and managing effective consumer relations. J. Product and Brand Manage., 7: 27-40.

4. Terril, C. and Middle-Brooks and AMA, 2000. Market Leadership Strategies for Service Companies: Creating Growth, Profits and Customer Loyalty. Lincolnwood: Contemporary Publishing.

5. Bharatwaj, S.G., P.R. Varadarajan and J. Fahy, 1993. Sustainable competitive advantages in service industries: Conceptual model and research propositions. J. Market., 57: 83-99.

6. Reichheld, F. and W.E. Sasser, 1990. Zero defections: Quality comes to services. Harvard Business Rev., 68: 105-111.

7. Sheth, J.N. and A. Parvatiyar, 1995. Relationship marketing in consumer markets: Antecedents and consequences. J. Acad. Market. Sci., 23: 255-271.

8. Beerli, A., J.D. Martin and A. Quintana, 2002. A model of customer loyalty in retail banking market. Eur. J. Market., 38: 253-75.

9. Meidan, A., 1996. Marketing Financial Services. Macmillan Press. Hound Mills.

10. Trubik, E. and M. Smith, 2000. Developing a model of customer defection in the australian banking industry. Managerial Auditing J., 15: 199208.

11. Caruana, A., 2002. Service loyalty: The effects of service quality and the mediating role of customer satisfaction. Eur. J. Market., 36: 811-828. 
12. Luarn, P. and H. Lin, 2003. A customer loyalty model for e-service context. J. Electron. Comm. Res., 4: 156-167.

13. Murphy, J.A. 1996. Retail Banking. In Buttle, R. (Ed.). Relationship Marketing: Theory and Practice. Paul Chapman, London, pp: 74-90.

14. Osman, M.Z., 1993. A conceptual model of retail images on loyalty patronage behaviour. The International Review of Retail Distribution and Consumer Research, 31: 149-66.

15. Andreassen, T. and B. Lindestad, 1998. Customer loyalty and complex services. Intl. J. Service Industry Manage., 9: 7-23.

16. Dwyer, R.F., P.H. Schurr and S. Oh, 1987. Developing buyer-seller relationships. J. Market., 51: 11-27.

17. Morgan, R.M. and S.D. Hunt, 1994. The commitment-trust: Theory of relationship marketing. J. Market., 58: 20-38.

18. Crosby, L.A., K.R. Evans and D. Cowles, 1990. Relationship quality in services selling: An interpersonal influence perspective. J. Market., 59: 68-81.

19. Guiltinan, J.P., 1989. A Classification of Switching Costs: With Implications for Relationship Marketing. In Childers, T.L. and Bagozzi, R.P. (Eds.). Proceedings of AMA. Winter Educators' Conference: Marketing Theory and Practice. AMA, Chicago, II, pp: 216-220.

20. Blomer, J. and J.D.P. Casper, 1995. The complex relationship between consumer satisfaction and brand loyalty. J. Econ. Psychol., 16: 311-29.
21. Bloemer, J., K. Ruyter and P. Peeters, 1998. Investigating drivers of bank loyalty: The complex relationship between image, service quality and satisfaction. Intl. J. Bank Market., 16: 276-86.

22. De Ruyter, K., M. Wetzels and J. Bloemer, 1998. On the relationship between perceived service quality, service loyalty and switching costs. Intl. J. Service Industry Manage., 9: 436-53.

23. Rundle-Thiele, S. and M.A. Mackay, 2001. Assessing the performance of brand loyalty measures. J. Services Market., 15: 529-546.

24. Harris, L.C. and M.M.H. Goode, 2004. The 4 levels of loyalty and the pivotal roles of trust: A study of online service dynamics. J. Retailing, 80: 139-158.

25. Kim, J.-O. and C.W. Mueller, 1978a. Introduction to factor analysis: What it is and how to do it. Thousand Oaks, CA: Sage Publications, Quantitative Applications in the Social Sciences Series, No. 13.

26. Joreskog, K., 1969. A general approach to confirmatory maximum likelihood factor analysis. Psychometrica, 34: 183-202.

27. Laroche, M., J. Bergeron and C. Goutaland, 2001. A three dimensional scale of intangibility. $J$. Service Res., 4: 26-38.

28. Nunnally, J.C. and I.H. Bernstein, 1994. Psychometric Theory. New York: McGraw-Hill. 